\title{
A regulamentação dos jardins botânicos brasileiros: ampliando as perspectivas de conservação da biodiversidade ${ }^{1}$
}

\author{
Oraida Maria Urbanetto de Souza Parreiras ${ }^{2}$
}

\section{RESUMO}

As tentativas de reverter o fracasso no desenvolvimento e na gestão do meio ambiente estão ligadas ao êxito das propostas relativas aos conceitos, ainda em construção, de desenvolvimento sustentável e de conservação da biodiversidade.

Os jardins botânicos direcionam, hoje, sua atuação para os problemas da conservação, na interface entre a conservação in situ e ex situ, objetivando a preservação da biodiversidade, e buscam uma estratégia comum para implementar políticas e ações para a conservação, ganhando destaque uma estratégia mais voltada para a flora local, aliada a outras formas de contribuição para a sustentabilidade ambiental do planeta.

O objetivo deste trabalho é efetuar uma análise crítica da Resolução/CONAMA 266, que estabelece diretrizes para a criação, normatiza o funcionamento, define os objetivos e uma classificação para os jardins botânicos brasileiros.

A análise do processo de regulamentação em curso evidencia a necessidade de aperfeiçoar a Resolução 266 - vista e entendida à luz das principais questões ambientais que compõem o momento histórico atual; muito além de mero instrumento normativo, deve ser entendida como um elemento para promover o desenvolvimento dos jardins botânicos, na perspectiva colocada pela necessidade da conservação da diversidade biológica e da promoção do uso sustentável dos recursos naturais.

Palavras-chave: jardins botânicos, regulamentação, conservação, legislação brasileira

\begin{abstract}
Botanical gardens around the world are now committed with preservation matters, mainly in the field of biodiversity maintenance, acting between in situ and ex situ conservation. They look for common strategies in the planet environmental sustainability, especially those directed to the local flora.

The purpose of this work is to undertake a critical analysis of the Resolução CONAMA 266, the legal text that fixes guidelines for the creation of Brazilian botanical gardens, with definitions of aims and operational norms, also including a structure for their classification.

One of the conclusions of the analysis refers to the necessity of revising the Resolução 266, in the light of the main environmental questions that have been arising recently. Far beyond a pure set of norms, it must be regarded as an instrument to promote the development of Brazilian botanical gardens, as demanded by the sustainable use of natural resources, with emphasis in the biodiversity conservation.
\end{abstract}

Key words: botanic gardens; norms; plants conservation; Brazilian legislation

\section{INTRODUÇÃO}

O jardim está presente no imaginário humano desde o princípio, para muitos povos. Adão e Eva, os primeiros seres humanos a habitar a Terra, viveram num Jardim, no Éden. Historicamente, supõe-se que jardins rudimen- tares começaram a ser construídos quando o homem deixa de ser nômade e passa a cultivar plantas; teriam assim uma função utilitária. Com o tempo ele agrega valores simbólicos, culturais e estéticos e desempenha, hoje, funções sociais e ecológicas (Rocha, 1999).

${ }^{1}$ Parte do Projeto de Final de Curso submetido, ao corpo docente do Programa de Formação Profissional em Ciências Ambientais da Universidade Federal do Rio de Janeiro.

${ }^{2}$ Instituto de Pesquisas Jardim Botânico do Rio de Janeiro - Rio de Janeiro, RJ. oraidaparreiras@ @otmail.com 
Os ancestrais europeus do que hoje se considera um jardim botânico eram, no princípio, ligados ao cultivo de plantas medicinais. Como resultado do conhecimento da exuberante flora do Novo Mundo, tiveram um grande impulso no século XVIII, quando foram construídos novos jardins botânicos e estufas para abrigar plantas tropicais.

Ao longo da história, o papel dos jardins botânicos sofreu transformações para além do estudo sistemático e científico. Hoje eles assumem funções na conservação ex situ, principalmente de espécies vulneráveis ou raras, ameaçadas de extinção ou mesmo extintas do meio natural, e direcionam sua atuação para os problemas da conservação, na interface entre a conservação in situ e ex situ, objetivando a preservação da biodiversidade.

Dessas transformações dos jardins botânicos, decorreram outras, menos visíveis, de caráter institucional, pois foi necessário, para desempenhar os diversos papéis que foram assumindo ao longo da história, buscar uma estruturação institucional capaz de sustentar a implementação das estratégias que em cada momento foram adotadas.

Um jardim botânico subordinado a uma política inadequada degenera-se muito rapidamente. Decorre disto, principalmente, a importância da regulamentação da atuação dos jardins botânicos, numa perspectiva de garantir o seu desenvolvimento e fortalecimento institucional.

A regulamentação em curso, bem como a forma proposta para implementá-la, podem contribuir para fortalecer os jardins botânicos e instrumentalizar uma etapa fundamental de seu engajamento mais efetivo no esforço mundial para superar os problemas ambientais do presente, por meio do desenvolvimento das práticas de conservação e preservação da diversidade biológica, da flora em particular.

Este trabalho pretende fundamentar teoricamente a importância da regulamentação dos jardins botânicos brasileiros; analisar a aplicação da Resolução/CONAMA 266, considerando, em particular, os elementos apresentados à Comissão Nacional de Jardins Botânicos - CNJB. Pretende também analisar o estágio atual de instrumentalização da Resolução 266, bem como os desafios colocados para aperfeiçoar a legislação específica dos jardins botânicos - na perspectiva do aprimoramento institucional, exigido pelos esforços de conservação da flora, para promover a sustentabilidade e o desenvolvimento socioambiental.

Implementar estratégias de conservação implica em combinar políticas, ações e saberes diversos, bem como numa estruturação institucional capaz de sustentar essa implementação. Assim, o presente trabalho justifica-se pela necessidade de ser criado um processo consistente de aplicação da Resolução/ CONAMA 266, instrumento fundamental para o fortalecimento dos jardins botânicos brasileiros, dentro da perspectiva - antes enunciada - de torná-los instituições mais eficazes na luta pela conservação da biodiversidade.

\section{METODOLOGIA}

A fim de abordar, em grandes linhas, as questões mais cruciais para situar o meio ambiente como uma preocupação global e central, recorremos à pesquisa em bibliografia especializada e na legislação pertinente ao tema.

Foram também utilizados, como referência, trabalhos feitos anteriormente para criar e implantar o Sistema Nacional de Registro dos Jardins Botânicos, disponibilizados na home page do Instituto de Pesquisas Jardim Botânico do Rio de Janeiro- JBRJ. Um desses trabalhos envolveu o uso de metodologias de pesquisa: levantamento e tratamento de dados, a partir de entrevistas com especialistas de diferentes áreas do Instituto. Na parte que trata do histórico da Resolução 266, recorremos à pesquisa documental, no Processo $\mathrm{n}^{\circ}$ 02001.000117/94-16/IBAMA e MMA, arquivado no Ministério do Meio Ambiente, e nas atas das reuniões da Comissão Nacional de Jardins Botânicos - CNJB/CONAMA. 
A regulamentação dos jardins botânicos brasileiros: ampliando as perspectivas de conservação da biodiversidade

\section{RESULTADOS E DISCUSSÃO}

\section{O meio ambiente e a conservação da diversidade biológica}

Situando a discussão sobre meio ambiente:

O que significa meio ambiente?

Trata-se de um conceito científico ou de uma representação social?

O que é um conceito científico?

O que é uma representação social?

Embora propostas para discutir educação ambiental, as perguntas acima, formuladas por Reigota (2001), são preliminares ao trato da problemática ambiental, pois suas respostas evidenciam dois componentes da abordagem às questões do meio ambiente: o componente das ciências naturais e o das ciências sociais.

Os conceitos científicos caracterizam o consenso da comunidade científica internacional em relação a um determinado conhecimento. São termos entendidos e utilizados univer-salmente como científicos: nicho ecológico, ecossistema, fotossíntese, são exemplos desta ordem de conceitos.

Uma representação social é o senso comum sobre determinado tema, onde se incluem os preconceitos, ideologias e características específicas das atividades cotidianas das pessoas, (Moscovici apud Reigota, 2001).

As representações sociais, embora também possam estar presentes na comunidade científica, relacionam-se com as pessoas fora desse âmbito. No entanto, nessas representações os conceitos científicos podem ser encontrados da forma que foram aprendidos e internalizados pelas pessoas.

A dupla composição da abordagem ciências sociais e naturais, aliada à própria complexidade de seu objeto, determina a dificuldade para definir o meio ambiente, resultando esse esforço, segundo Maimon (1992), em definições relativas e mutantes no tempo, dependentes do centro de interesse do trabalho científico e diferenciando-se em função do campo disciplinar.

De acordo com Reigota (2001), não há consenso sobre o conceito de meio ambiente na comunidade científica e nem fora dela.
Considera, por seu caráter difuso e variado, a noção de meio ambiente uma representação social e, por julgar outras definições restritivas, define meio ambiente como:

"O lugar determinado ou percebido, onde os elementos naturais e sociais estão em relações dinâmicas e em interação. Essas relações implicam processos de criação cultural e tecnológica e processos históricos e sociais de transformação do meio natural construído".

Esta nos parece ser a abordagem mais adequada de meio ambiente para este trabalho, pois permite discutir a questão ambiental numa perspectiva mais ampla, abrangendo inclusive a ação humana na busca de alternativas para uma melhor relação com o meio ambiente, que no nosso caso particular, resulta na formulação de política pública e instrumentos de ação ambiental específicos.

\section{O meio ambiente e a crise ambiental como questões globais}

"O eixo em que giram todos os empenhos do mundo é o reprocessamento. Empenhado em reprocessar todo o processo de suas dependências, o mundo instala um sistema de controle da cultura e da civilização que a vontade de poder vai realizando na ciência, na técnica, na produção. É o império das funções vigentes." (Leão apud Unger,2001)

As questões ambientais passam a constituir uma preocupação global na medida em que fica cada vez mais clara a percepção de que o sistema de produção vigente intensivo no uso de recursos naturais e altamente degradador do meio ambiente, traz o risco do esgotamento desses recursos, numa escala capaz de configurar uma crise sem precedentes na história humana.

No seu desenvolvimento o Capitalismo engendra sua própria destruição, afirmava Karl Marx, em meados do século XIX (Tavares, com. pes.).

O elemento destruição, inerente a esse modo de produção, no entanto, é voltado antes à vida do que a si próprio. Incauto, esgota e cria recursos sem a medida das conseqüências. 
Cego, baseia-se no lucro, na competição, no consumo e no desperdício em larga escala; materializa-se na acumulação privada de capital, na concentração de renda e na desigualdade social entre classes e nações.

É um sistema cuja ordem possível é a da exclusão social e econômica, da submissão dos mais pobres aos mais ricos, dos fracos aos fortes, dos menos aos mais desenvolvidos. Embora pareça paradoxal, é justamente o seu caráter excludente que o torna, muito além de hegemônico, global.

Uma vez instalado, o Capitalismo não comporta e não convive com outro modo de produção que se desvie dos seus fundamentos de espoliação do homem e da natureza. Pensamos que aí reside parte importante, e somente parte, da explicação para o fracasso das alternativas tentadas pelo Leste, nas quais a deterioração ambiental foi ainda mais intensa; ou seja: numa incapacidade de romper com as bases do modo de produção capitalista frente à pressão de sua globalidade excludente. Pois, ao se expressarem enquanto "socialismo real", aquelas alternativas desvelaram que ainda preservavam, nelas mesmas, fundamentos capitalistas essenciais.

\section{A natureza da crise}

"Em contraste com o mundo, a Terra evoca o proteger da proteção de que necessita o mundo para se construir em meio às dependências. Como quer que se determine a posição do mundo na história da cultura, a Terra lhe opõe sempre as tensões criadoras de sua proteção. É na força desta oposição que a Terra deixa de ser simples planeta integrante do Sistema Solar para ocupar lugar privilegiado no universo da realidade." (Leão apud Unger, 2001)

Trata-se esta de uma crise da modernidade que, de modo mais essencial, resulta de um desequilíbrio enraizado no coração do homem. Repõe questões que fundamentam o percurso de uma época. A grande diferença entre a nossa e as civilizações precedentes é que: “...enquanto outras sociedades fizeram do eixo de sua cultura a elaboração de técnicas para controlar a tendência humana àquele desejo desmesurado que os gregos chamavam híbris, a nossa fez da híbris sua virtude máxima. O projeto de dominação e controle de tudo que existe forma o eixo em torno do qual esta civilização gravita.” (Unger, 2001)

Um olhar mais atento sobre a natureza da crise hoje experimentada pela humanidade nos remete ao seu sentido etimológico: do grego krínein, que significa discernir, decidir. Significado este que empresta ao sentido global desta crise um caráter ainda mais amplo, além da simples percepção de que ela extrapola limites sócio-econômicos, de fronteiras nacionais e de classes sociais.

Decidir sobre qual é o seu lugar no universo é tarefa urgente para o homem. Essa decisão deve partir da compreensão do próprio sentido original de crise, que traz em si os elementos de sua superação: discernimento e decisão. São estes, elementos fundamentais para o enfrentamento de uma crise de caráter complexo, do mundo para a Terra, e que se manifesta em múltiplas dimensões.

\section{A crise do mundo na Terra}

"Vista do espaço, a Terra é uma bola frágil e pequena, dominada não pela ação e pela obra do homem, mas por um conjunto ordenado de nuvens, oceanos, vegetação e solos. $\mathrm{O}$ fato de a humanidade ser incapaz de agir conforme essa ordenação natural está alterando fundamentalmente os sistemas planetários. Muitas dessas alterações acarretam ameaças à vida. Esta realidade nova, da qual não há como fugir, tem de ser reconhecida - e enfrentada." (CMMAD, in Nosso Futuro Comum, 1988)

Os indícios mais antigos da ação antrópica, já apontam um grau considerável de perturbação no meio ambiente. Dean (1996), chama a atenção para o fato de que todos os regimes agrícolas, inclusive os mais primitivos, representam transtornos a um ecossistema natural. No entanto, as perturbações antrópicas 
A regulamentação dos jardins botânicos brasileiros: ampliando as perspectivas de conservação da

passam a configurar uma condição de desequilíbrio - mais notadamente a partir da Revolução Industrial - que assume um caráter crítico desde a segunda metade do século passado.

Por um lado, o desempenho econômico, científico e tecnológico, experimentado no último século numa escala sem precedentes, traz indicadores animadores: aumento da expectativa de vida, redução da mortalidade infantil e do analfabetismo, aumento da produção mundial de alimentos maior do que o aumento da população.

Por outro lado, é grande o contraste retratado no mundo, que não reflete uma distribuição eqüitativa desses benefícios: há, em termos absolutos, mais famintos no mundo do que nunca; cresce o déficit habitacional; amplia-se o fosso entre nações ricas e pobres, e, dadas às circunstâncias atuais e as disposições institucionais vigentes, há poucas perspectivas de que essa tendência se inverta.

Existem também tendências ambientais que ameaçam modificar radicalmente o planeta e ameaçam a vida de muitas espécies, incluindo a espécie humana: desflorestamento, desertificação, poluição do ar, das águas e do solo. Na Europa, as chuvas ácidas matam florestas e lagos e danificam o patrimônio artístico e arquitetônico das nações.

Some-se a isso o fato de os países em desenvolvimento, que devido a fatores históricos e geográficos são detentores da maior parte dos recursos naturais hoje existentes, atuarem num contexto em que se amplia o fosso que os separa dos países industrializados. Estes, que para o próprio desenvolvimento já consumiram, e continuam a consumir grande parte dos recursos do planeta, impõem as normas que regem as principais organizações internacionais, configurando um desequilíbrio também de poder.

Assim, perpetua-se o circulo vicioso: miséria-degradação ambiental, degradação ambiental-miséria.

\section{Um outro mundo é possível}

"No passado, a análise repousava sobre o equilíbrio dos sistemas naturais e sobre o estudo da estabilidade global; agora estamos no campo da incerteza e da gestão a longo prazo." (Maimon, 1994)

No campo da ciência da natureza, para muitos autores é cada vez mais evidente que a ciência clássica, baseada em pretensas objetividade e neutralidade científica, não é capaz de responder aos desafios hoje colocados.

Segundo Reigota, (2001), Prigogine e Stengers propõem o que chamam de uma "escuta poética da natureza, reintegrando o homem no universo que ele observa", e no qual atua, acrescente-se. Reigota alerta que essa idéia, embora corra um risco de banalização, se entendida como uma relação idílica, visa chamar a atenção para a importância dos sentidos e da subjetividade nas relações cotidianas com a natureza. Ou seja: estabelecer um diálogo com ela, considerando, antes de tudo, seu caráter complexo e múltiplo, questionando o paradigma racionalista da ciência e da exploração dos recursos naturais.

Rompendo com o monólogo e propondo o diálogo, a natureza "responde" às indagações feitas pelos cientistas e estes precisam decifrar tais respostas, como alguém que faz uma leitura, entre outras possíveis, das mesmas. Neste sentido, a ciência contemporânea relativiza o conhecimento e desestabiliza o poder das "verdades científicas", procura conhecer os momentos de estabilidade e de instabilidade, assim como os acontecimentos raros e aleatórios do universo, normalmente deixados de lado pelos cientistas clássicos (Reigota, 2001)

Para Maimon, (1992), situada a ciência no campo da incerteza, a complexidade do meio ambiente não pode ser compreendida - nem resulta - de um concurso e integração de muitos e diferentes campos de conhecimento: a escolha das disciplinas depende do fenômeno a ser analisado. A implantação da interdisciplinaridade caminha do particular em 
direção ao geral, do simples ao complexo, do nível disciplinar à multidisciplinaridade.

Assim, a análise das questões envolvidas no meio ambiente, incluindo as alternativas capazes reverter o atual cenário de crise, demandam uma visão sistêmica e um pensamento holístico, um novo paradigma científico, que integra o campo das ciências naturais e sociais.

O componente social se apresenta na análise ambiental a partir da década de 60, quando passa a ser estabelecida uma relação de causa e efeito, entre o crescimento econômico e a deterioração do meio ambiente e o esgotamento dos recursos naturais. Esse componente coloca também em pauta as transformações necessárias para tornar a sociedade compatível com estratégias alternativas de desenvolvimento, trazendo para a ordem do dia a gestão do meio ambiente em longo prazo:

Segundo Young (com. pes.), o Clube de Roma, em seu relatório de 1968, "Limites do Crescimento" atribui a deterioração ambiental e o esgotamento dos recursos naturais ao resultado da pressão do crescimento demográfico sobre os recursos limitados do planeta. Essa pressão faria com que o preço das matérias primas aumentasse e a disponibilidade de alimentos diminuísse, a ponto de não comportar mais nenhum desenvolvimento. A proposta de "crescimento zero" daí decorrente condenaria os países desenvolvidos à estagnação e os menos desenvolvidos à indigência perpétua. As previsões do Clube de Roma não se verificaram, os preços das matérias primas decresceram e a produção de alimentos cresceu.

Em 1972, realiza-se a Conferência de Estocolmo, a questão ambiental é, então, recolocada em novo eixo: a Declaração de Estocolmo, reconhece a qualidade ambiental como um direito da humanidade, ao lado de outros direitos humanos fundamentais, como liberdade, igualdade e condições de vida adequadas. Ao estabelecer como obrigação da humanidade proteger e melhorar o meio ambiente para as gerações presentes e futuras, esse documento lança as bases para o conceito de desenvolvimento sustentável:

“... aquele que atende às necessidades do presente sem comprometer a possibilidade de as gerações futuras atenderem as suas próprias necessidades." (CMMAD, in Nosso Futuro Comum, 1998).

Esta definição contém dois conceitoschave: o de "necessidades", determinadas social e culturalmente, e a noção das limitações que o estágio da tecnologia e da organização social impõe ao meio ambiente comprometendo sua capacidade de atender às necessidades presentes e futuras. Sustentabilidade implica, então, numa visão atemporal das necessidades e do bem estar da humanidade, que incorpora variáveis não-econômicas, como: educação, saúde e qualidade de vida, como direitos do ser humano e dever da sociedade.

De acordo com Viederman (apud Lagos, 1998), a sustentabilidade não deve ser tratada como um problema técnico, mas como uma visão do futuro que nos dá um mapa dos caminhos e nos ajuda a focar a atenção na afirmação dos valores e princípios morais e éticos, que devem ser transferidos para as decisões políticas capazes de promovê-la.

As tentativas de reverter o fracasso no desenvolvimento e na gestão do meio ambiente emprestam um sentido mais preciso àquela decisão fundamental que a crise nos coloca: qual o lugar do homem no universo. Este caminho de decisão requer a opção pela sustentabilidade socioambiental, a partir da qual pode ser possível construir um mundo novo onde o desenvolvimento prescinda da base, hoje estruturada, de espoliação do homem e da natureza.

\section{Extinção, fenômeno natural e resultado da ação humana}

“... a irreversibilidade dos sistemas físicos em desequilíbrio tem um papel construtivo na natureza, pois lhe permite (e exige) a reorganização e a auto-organização. Portanto a irreversibilidade e a instabilidade são fontes 
A regulamentação dos jardins botânicos brasileiros: ampliando as perspectivas de conservação da

criadoras de novas formas de organização." (Reigota, 2001)

Costa (2002) coloca a discussão nos seguintes termos: Por que se faz tanto alarde atualmente contra a perda de biodiversidade? Simplesmente porque a taxa de extinção número de espécies perdidas por unidade de tempo - aumentou dramaticamente nas últimas décadas. As perdas atuais de espécies têm sido contabilizadas, pelos conservacionistas, numa escala graduada em dias ou mesmo em horas! Múltiplas evidências de extinção em massa provocadas por populações humanas têm sido encontradas em praticamente todas as regiões da Terra, mas nunca tantas espécies, ao que tudo indica, foram perdidas em um intervalo tão curto de tempo.

Pode-se afirmar, então, que as advertências sobre o risco de extinção em massa de espécies, que compromete a diversidade biológica, referem-se ao volume e às escalas de tempo e amplitude geográfica em que esta extinção vem ocorrendo, levando em conta o tempo que a natureza necessita para reorganizar-se ou evoluir.

A reversão deste quadro está ligada ao êxito das propostas relativas aos conceitos, ainda em construção, de desenvolvimento sustentável e de conservação da biodiversidade, temas que, por guardarem uma relação de interdependência intrínseca, são indissociáveis.

\section{Conservação e diversidade biológica, enquanto conceitos}

"Os sistemas, como vegetação (principalmente as florestas), desempenham uma função de proteção, da estrutura e integridade do solo, da formação e manutenção de bacias hidrográficas, da fauna local, do ambiente térmico, entre outros componentes do meio. [...] a conservação de tais elementos se constitui hoje em compromisso de responsabilidade das nações que os detém, principalmente os signatários da Convenção sobre a Diversidade Biológica - CDB." (Pereira, com. pes.)

Diversidade biológica, ou biodiversidade significa:

"A variabilidade de organismos vivos de todas as origens, compreendendo, dentre outros, os ecossistemas terrestres, marinhos e outros ecossistemas aquáticos e os complexos ecológicos de que fazem parte; compreendendo ainda a diversidade dentro de espécies, entre espécies e de ecossistemas". (BRASIL, 1994)

A Conservação, enquanto disciplina, está relacionada à gestão da crise ambiental e apóia seu conteúdo sobre uma base teórica que utiliza princípios das ciências naturais e sociais. Pode ser, então, definida como: a gestão racional dos recursos ambientais com vistas à sua utilização, de forma a satisfazer as necessidades humanas atuais e das gerações futuras.

De acordo com Pereira (com. pes.), refere-se à utilização sustentável dos recursos da biodiversidade, guardando com esta uma relação em três níveis: diversidade genética dentro de uma mesma espécie, de espécies e de ecossistemas.

Constituem-se em forma de manejo compreendido como o conjunto de práticas e procedimentos técnicos e administrativos preestabelecidos, adequado ao objeto a ser conservado - a conservação in-situ, que significa a conservação dos recursos biológicos no seu local de origem, dentro dos ecossistemas ou habitats; e a conservação ex-situ, que, complementar à anterior, significa a conservação dos recursos biológicos fora do seu local de ocorrência. Este assunto deverá ser mais detalhado quando falarmos a respeito do papel dos jardins botânicos na conservação.

\section{Instrumentos e diretrizes internacionais para políticas de conservação dos jardins botânicos}

"Recentemente, a preocupação para com o meio ambiente mundial conduziu a um avanço significativo na cooperação internacional, nas questões de desenvolvimento e nos temas ambientais. Como parte disto, foram desenvolvidos sistemas internacionais para guiar países na formulação de suas políticas nacionais". (BGCI, 2001) 
A seguir apresentaremos os instrumentos e diretrizes internacionais, considerados mais relevantes para os jardins botânicos guiarem os seus trabalhos, globalmente, para a conservação da flora, conforme relacionados nas Normas Internacionais de Conservação para os Jardins Botânicos, BGCI (2001), onde estão propostas as estratégias que orientam a ação destes pelas diretrizes conservacionistas estabelecidas nos foros internacionais mais atuais:

Convenção sobre Terras Úmidas, 1971.

Passando a vigorar em 1975, foi originalmente organizada para proteger os habitats das terras úmidas para a conservação das aves aquáticas, tendo ampliado seu escopo: hoje é um tratado internacional que prevê uma ação nacional e a cooperação internacional para a conservação e o uso racional das terras úmidas e de seus recursos.

Convenção sobre Proteção do Patrimônio Cultural e Natural do Mundo, 1972

Derivada da necessidade de estimular a cooperação internacional para proteger e preservar o patrimônio cultural e natural do mundo para estas e para as futuras gerações. Define quais os tipos de sítios naturais e culturais que podem ser indicados para inscrição na Lista do Patrimônio Mundial. Uma vez incluídos na Lista beneficiam-se do apoio da comunidade internacional em termos de proteção e preservação.

Em 1997, o Jardim Botânico da Universidade de Pádua, Itália, foi o primeiro jardim a constar da Lista. Este ano foi inscrito o Instituto de Pesquisas Jardim Botânico do Rio de Janeiro.

Agenda 21 - Programa de Ação para o Desenvolvimento Sustentável, 1992

Concebido na Conferência da Terra, Rio, 92, trata-se de um plano de ação para uma sociedade global com o objetivo de promover a cooperação entre nações, enquanto elas promovem a transição para a sustentabilidade.

Falta à Agenda 21 a força do Direito Internacional; sua adoção, porém, se constitui em forte obrigação moral dos governos, e compromisso de todas as instituições, inclusive os jardins botânicos, e grupos sociais empenhados em promover o desenvolvimento sustentável.

Convenção das Nações Unidas sobre Mudanças Climáticas, 1992

Trata-se de um acordo internacional desenvolvido em função da preocupação de que as atividades humanas afetem o clima global e comprometam as condições básicas de vida na terra. Seu objetivo maior é o de estabilizar as concentrações de gases nocivos na atmosfera, que contribuem para aumentar o efeito estufa, e prevenir maiores interferências humanas no sistema climático.

Há um importante papel reservado aos jardins botânicos no sentido de ajudarem seus países a cumprir tais compromissos.

Convenção sobre a Diversidade Biológica CDB, 1992

A CDB, foi firmada por 150 países, no Rio de Janeiro, em 05/06/1992, na Conferência das Nações Unidas sobre o Meio Ambiente e Desenvolvimento, também conhecida como Eco 92 ; é composta de 42 artigos.

No artigo 1 constam seus objetivos:

I - conservação da diversidade biológica, II - a utilização sustentável de seus componentes e

III - repartição justa e eqüitativa dos benefícios derivados da utilização dos recursos genéticos, mediante, inclusive, o acesso a estes recursos e a transferência adequada de tecnologia, considerados os direitos sobre recursos e tecnologias, mediante financiamento adequado.

Convenção das Nações Unidas para o Combate à Desertificação, 1994

Foi adotada com o objetivo de promover ações efetivas por meio de programas locais inovadores e parcerias internacionais. Convoca os governos a se concentrarem na conscientização, educação e treinamento, tanto nos países em desenvolvimento quanto nos desenvolvidos.

A atuação dos jardins botânicos pode 
concorrer para o alcançar os objetivos desta Convenção, como já vem ocorrendo, particularmente nas regiões secas do mundo.

Plano Global de Ação para a Conservação e Utilização Sustentável de Recursos Genéticos de Plantas para a Alimentação e Agricultura, $\underline{1996}$

Desenvolvida pela FAO - Organização das Nações Unidas para Alimentação e Agricultura, cujos objetivos são: assegurar a conservação dos recursos genéticos vegetais para a alimentação e agricultura como base para a segurança alimentar; promover o uso sustentável dos recursos genéticos vegetais para a alimentação e agricultura, estimular o desenvolvimento e reduzir a fome e a pobreza; promover o compartilhamento justo e eqüitativo dos benefícios derivados do uso dos recursos genéticos vegetais e ajudar países e instituições a identificarem as prioridades de ação fortalecendo os programas existentes.

O Plano observa que os jardins botânicos são importantes para a conservação dos recursos genéticos, por meio da manutenção de coleções vivas, bancos de sementes e coleções in vitro.

Convenção sobre Comércio Internacional de Espécies da Fauna e Flora Silvestre em Extinção - CITES

Tem o objetivo de controlar o comércio internacional de espécies da fauna e da flora em extinção. Permite o comércio de espécies que ainda sejam passíveis de exploração econômica, prevenindo, entretanto, que esse comércio não venha trazer o risco de extinção dessas espécies.

O Botanic Gardens Conservation International - BGCI, elaborou um manual da CITES para os jardins botânicos, pois considera que estes têm um papel central no aperfeiçoamento e na implementação desta Convenção, inclusive, no que diz respeito à conscientização pública.
A convenção sobre a diversidade biológica, o papel dos jardins botânicos na conservação e a legislação brasileira

A CDB - um marco para a conservação e o desenvolvimento sustentável

"A Convenção pode ser considerada como um marco por diversas razões. Pela primeira vez a diversidade biológica, como tal, é abordada numa perspectiva integral e a diversidade genética abordada especificamente em um tratado global vinculatório. Também, pela primeira vez, se reconhece a conservação da diversidade biológica como do interesse comum da humanidade".(Glowka, 1996)

A CDB reconhece e afirma a soberania das nações sobre seus recursos biológicos e permite que as Partes - países signatários determinem como deverá ser implementada, equilibrando essa soberania com os deveres, dela própria derivado

Os jardins botânicos e a CDB

“... As coleções dos jardins botânicos e a aplicação de suas habilidades em áreas como taxonomia, pesquisa botânica, conservação, propagação e cultivo contribuem significativamente na implementação da CDB. Eles também oferecem uma ligação principal entre a conservação in-situ e ex-situ e são freqüentemente envolvidos em processos de planejamento nacionais como estratégias de biodiversidade. Seu trabalho em outros setores ilustra o papel importante que eles podem fazer implementando a Convenção". (BGCI, 2001)

Nas Normas Internacionais de Conservação para Jardins Botânicos, são identificados, e listados, 10 artigos da CDB que podem ser diretamente implementados pelos jardins botânicos. Rauer (2000), complementa esta lista e, numa análise mais detalhada da importância da Convenção para os jardins botânicos, estabelece quatro categorias de artigos que estes devem levar em conta em suas ações: artigos com os quais podem contribuir para viabilizar o cumprimento, artigos que podem ajudar a impedir sejam violados; artigos que podem ser postos diretamente em prática, e finalmente aqueles que não guardam 
interesse imediato para essas instituições.

Relacionamos a seguir 12 artigos, extraídos dessas contribuições, que podem ser implementados diretamente pelos jardins botânicos:

Artigo 6 - Medidas gerais para a conservação e a utilização sustentável

Contribuindo na formulação e implementação das estratégias nacionais para a sustentabilidade dos recursos biológicos e do desenvolvimento.

Artigo 7 - Identificação e monitoramento

Empreendendo trabalhos de taxonomia, florística, inventários, monitoramento e demais pesquisas botânicas.

Artigo 8 - Conservação in situ

Contribuindo mediante identificação e indicação de áreas a serem protegidas; manutenção e administração dessas áreas; desenvolvimento de pesquisas em restauração ambiental, recuperação ou manejo de populações de plantas silvestres.

\section{Artigo 9 - Conservação ex situ}

Desenvolvendo e mantendo coleções de germoplasma, inclusive bancos de sementes, bancos genéticos a campo, coleções de tecido vegetal em cultura, programas de recuperação de espécies ameaçadas e bancos de dados.

Artigo 10 - Utilização sustentável de componentes da diversidade biológica

Identificando e desenvolvendo bioprospecção de espécies economicamente importantes para a horticultura comercial, silvicultura e agricultura.

\section{Artigo 12 - Pesquisa e treinamento}

Empreendendo pesquisa em muitos campos pertinentes, como taxonomia, ecologia, bioquímica, etnobotânica, educação, horticultura, anatomia das plantas, biogeografia, e oferecendo oportunidades de treinamento e cursos sobre conservação e disciplinas afins.

Artigo 13 - Educação e conscientização pública

Promovendo a educação pública e desenvolvendo a conscientização ambiental, inclusive programas para gerar a compreensão pública acerca da biodiversidade, sua importância e os danos sofridos. Muitos jardins botânicos já desempenham papéis importantes no ensino fundamental e superior.

Artigo 14 - Avaliação de impacto e minimização de impactos negativos

Contribuindo com conhecimentos específicos e pesquisas científicas, bem como por meio de seu corpo de especialistas, os jardins botânicos podem auxiliar na recomendação de práticas para prevenir e avaliar impactos ambientais de diversas ordens, e na elaboração e execução de projetos de recuperação ambiental.

Artigo 15 - Acesso a recursos genéticos (e repartição de benefícios)

Apoiando as instituições que fazem pesquisas em conservação da biodiversidade por meio da coleta de táxons, apoio a pesquisas, equipamentos, informação treinamento e intercâmbio de espécimes; assim como oferecendo acesso a seus recursos de conservação da biodiversidade. Contribuindo e influenciando na regulamentação legal desse artigo.

Artigo 16 - Acesso à tecnologia e transferência de tecnologia

Os jardins botânicos possuem um acúmulo muito grande de conhecimentos derivados das pesquisas nos campos da Botânica e de áreas correlatas. Grande parte dessas pesquisas resulta no desenvolvimento de tecnologias e metodologias relacionadas com técnicas de cultivo, crescimento e reprodução das plantas em condições ex-situ. Esses resultados podem ser disponibilizados, além da representação didática das plantas para propósitos educacionais.

Artigo 17 - Intercâmbio de informações

Disponibilizando informações sobre suas coleções e o resultado de suas pesquisas através de publicações e de bancos de dados.

Artigo 18 - Cooperação técnica e científica

Cooperando nas áreas científicas e técnicas, inclusive pesquisa conjunta e intercâmbio de pessoal. 
A regulamentação dos jardins botânicos brasileiros: ampliando as perspectivas de conservação da

biodiversidade

O papel dos jardins botânicos na conservação da flora - potencialidades e limites

“... A maior parte das coleções de espécies silvestres e plantas ornamentais, fora de seu local de origem, se encontra sob custódia dos 1600 jardins botânicos, em todo o mundo. Juntos eles cuidam de representantes de dezenas de milhares de espécies vegetais..." (Tuxill, 1999)

Os jardins botânicos são instituições que ao longo de sua história têm contribuído para a conservação da flora mundial e como não poderia deixar de ser, não apenas acompanham, mas inserem-se ativamente na dinâmica do desenvolvimento das questões relativas ao trato do meio ambiente.

Sob a denominação de jardim botânico pode ser incluída uma grande diversidade de instituições. Estas variam desde grandes jardins com centenas de funcionários e uma extensa gama de atividades, até instituições pequenas com atividades e recursos limitados. (BGCI, 2001).

As diferenças entre os jardins botânicos não impedem uma estratégia comum, pois conferem ao conjunto um papel complementar na implementação de políticas e ações para a conservação da flora.

$\mathrm{O}$ quadro ambiental crítico que tem se apresentado, trouxe a necessidade de uma redefinição estratégica e de uma formulação e avaliação permanente das políticas dessas instituições. Hoje, ganha destaque uma estratégia mais voltada para a conservação da flora local, aliada a outras formas de contribuição para a sustentabilidade ambiental do planeta.

Todas essas questões fazem do planejamento, do desenvolvimento institucional e científico, da articulação dos jardins botânicos entre si, com instituições congêneres e com o conjunto da sociedade, instrumentos indispensáveis para o desempenho de seu papel.

\section{Estratégias de conservação para jardins botânicos}

A primeira estratégia global para jardins botânicos foi definida pela publicação, em 1989, da Estratégia de Conservação para Jardins Botânicos. Com as mudanças ocorridas no contexto ambiental nas últimas décadas, surgiu a necessidade de sua atualização.

Em 2001, por iniciativa conjunta do JBRJ e do Ministério do Meio Ambiente é feita, então, a publicação em Português das Normas Internacionais de Conservação para os Jardins Botânicos, BGCI (2001), que orienta a ação dos jardins botânicos de todo o mundo pelas diretrizes conservacionistas estabelecidas nos foros internacionais mais atuais.

A publicação das Normas Internacionais vem estabelecer critérios para definir a atuação dos jardins botânicos na conservação da diversidade florística, atentando para a necessidade destes implementarem as diretrizes da Convenção sobre Diversidade Biológica, contribuindo para o desenvolvimento sustentável e para a sustentabilidade ambiental do planeta. Sendo seus objetivos:

a) Promover uma estrutura global comum de políticas para jardins botânicos, programas e prioridades em conservação da biodiversidade. b) Definir o papel dos jardins botânicos no desenvolvimento de sociedades globais e em alianças para a conservação da biodiversidade. c) Estimular a avaliação e desenvolvimento de políticas e práticas de conservação em jardins botânicos para aumentar-lhes a efetividade e eficiência.

d) Desenvolver meios para monitorar e registrar as ações de conservação empreendidas por jardins botânicos.

e) Promover o bom desempenho dos jardins botânicos, em conservação.

f) Promover orientação para os jardins botânicos sobre temas contemporâneos acerca da conservação.

É missão global dos jardins botânicos na Conservação, segundo as Normas Internacionais:

- Interromper a perda de espécies de plantas e de sua diversidade genética em nível mundial. - Atentar para a prevenção da degradação do meio ambiente natural do mundo. 
- Ampliar o entendimento público sobre o valor da diversidade das plantas e sobre as ameaças que sofrem.

- Implementar ações práticas para o benefício e melhoria do meio ambiente natural do mundo.

- Promover e assegurar o uso sustentável dos recursos naturais do mundo para esta e para futuras gerações.

O desempenho da missão global e o alcance dos objetivos dos jardins botânicos requerem um trabalho conjunto com o maior número de parcerias possíveis: governos, ONGs, corporações empresariais, comunidades, entre outros.

\section{Diretrizes para conservação e a legislação brasileira}

\section{Legislação ambiental no Brasil:}

$\mathrm{Na}$ evolução do Direito ambiental brasileiro é possível observar três fases distintas, de acordo com Bittencourt (com. pes.).

A primeira delas, classificada como uma "fase de exploração" teve início em 1500, incorporando todas as regulamentações relativas à exploração dos recursos naturais da Colônia pela Metrópole, e, a partir da Independência seguiu regulamentando a exploração desses recursos, os direitos de usos e da propriedade privada.

A promulgação dos Códigos de Caça, Pesca e Florestal, em 1965, que definem os recursos naturais de uso comum como de propriedade do Estado, inaugura a "fase fragmentária" do Direito Ambiental brasileiro. Fragmentária porque nesta fase não se constituiu, ainda, um corpo de legislação que refletisse uma política de fato para o meio ambiente, embora tenha havido avanços além da regulamentação meramente exploratória.

A fase denominada "holística" ou "integradora" é inaugurada em 1981, com a Lei 6902, que trata da criação de Estações Ecológicas e Áreas de Proteção Ambiental, parte integrante da política nacional do meio ambiente, embora anterior à Lei 6938/81 - Lei da Política Nacional do Meio Ambiente, que consolidou essa nova fase. Considerada o divisor de águas na legislação do meio ambiente, a Lei 6938 norteia a ação dos entes públicos e estrutura a política ambiental no País.

Esta fase vem sendo desenvolvida até hoje, constituindo-se, ainda, fundamentais para o seu desenvolvimento: a Lei 7347/85 - Lei da Ação Civil Pública, que possibilita o ingresso de ações civis para prevenir ou reparar danos ambientais, e a própria Constituição Federal/ 88, que no Capítulo 6, Título 8 - Ordem Social Art. 225, impõe ao Poder Público o dever de defender e preservar o meio ambiente para presentes e futuras gerações e de assegurar a efetividade do direito de todos ao meio ambiente ecologicamente equilibrado.

Nesta fase consolidam-se os instrumentos atuais da Legislação Ambiental Brasileira, quais sejam: a Constituição Federal e o conjunto de Leis e Decretos, Convenções, Tratados e Normas Internacionais, Medidas Provisórias, Resoluções do CONAMA (atribuição delegada) e as Portarias Ministeriais, que a compõem.

\section{Instrumentos da legislação brasileira, específicos para os jardins botânicos}

Neste tópico relacionamos aqueles instrumentos específicos e os que orientam ou estão diretamente associados às atividades de conservação dos jardins botânicos brasileiros:

- Constituição Federal de 1988 - No seu Artigo 255 , estabelece o direito coletivo ao meio ambiente ecologicamente equilibrado e, no inciso II, afirma que, para assegurar a efetividade desse direito, incumbe ao poder público preservar a diversidade e a integridade do patrimônio genético do país e fiscalizar as entidades dedicadas à pesquisa e manipulação de material genético.

- CDB - Convenção sobre a Diversidade Biológica-1992-O Decreto Legislativo n. ${ }^{\circ} 2$, de 1994, aprovou o texto da Convenção sobre Diversidade Biológica, assinada durante a Conferência das Nações Unidas sobre Meio Ambiente e Desenvolvimento, realizada na cidade do Rio de Janeiro, em 05 de junho de 1992 , que é promulgada pelo Decreto $\mathrm{N}^{\circ} 2.519$, 
A regulamentação dos jardins botânicos brasileiros: ampliando as perspectivas de conservação da biodiversidade

de 16 de Março de 1998, passa a fazer parte, portanto, do corpo da legislação ambiental do País.

A CDB estabelece as diretrizes para: conservar a diversidade biológica no mundo; promover o uso sustentável dos seus componentes e a repartição eqüitativa dos benefícios advindos do uso e do acesso aos recursos genéticos, bem como a transferência de tecnologia associada ao seu uso.

- Normas Internacionais de Conservação para Jardins Botânicos - BGCI, MMA, JBRJ, RBJB, 2000-Embora sem força de lei, orienta critérios para definir a atuação dos jardins botânicos na conservação da diversidade florística, como visto anteriormente.

- Decreto No 4.339 de 22/08/2002 - Institui princípios e diretrizes para a implementação da Política Nacional da Biodiversidade.

- Medida Provisória 2186 de 23/08/2001 Dispõe sobre o acesso ao patrimônio genético, a proteção e o acesso ao conhecimento tradicional associado, a repartição de benefícios e o acesso à tecnologia e a transferência de tecnologia para sua conservação e utilização, e dá outras providências.

- Decreto-003945 de 28/09/2001 - Define a composição do Conselho de Gestão do Patrimônio Genético e estabelece as normas para o seu funcionamento, mediante a regulamentação dos artigos 10, 11, 12, 14, 15, 16, 18 e 19 da medida provisória 2.186-16.

- Resolução CONAMA 266, de 03/08/2000 Estabelece diretrizes para a criação de jardins botânicos, normatiza o funcionamento desses, define seus objetivos e cria a Comissão Nacional de Jardins Botânicos - CNJB, com a finalidade de assessorar a Secretaria Executiva do Conselho Nacional do Meio Ambiente, CONAMA, no acompanhamento e análise dos assuntos relativos a jardins botânicos. Esta resolução será objeto de detalhamento no próximo capítulo.

- Resolução CONAMA 287 de 30/08/2001 Complementa a Resolução 266, delegando ao Instituto de Pesquisas Jardim Botânico do Rio de Janeiro as competências do MMA relativas ao registro dos jardins botânicos e institui o registro e enquadramento provisórios.

- Moção/CONAMA n. ${ }^{\circ} 13$ - Também sem força de lei, foi proposta pela CNJB e aprovada na reunião ordinária do CONAMA de 14/05/ 2001, recomenda que em cada Estado da Federação, onde ainda não exista área definida, caracterizada e identificada como jardim botânico, sejam desenvolvidas ações nos níveis de governo estadual ou municipal.

\section{A Resolução CONAMA 266 e seu processo de implementação Um histórico da Resolução CONAMA 266}

No Processo $n^{\circ}$ 02001.000117/94-16/ IBAMA e MMA, estão registrados todos os documentos referentes à elaboração da Resolução 266, nele, encontram-se seis minutas de Projeto de Lei, propostas entre os anos de 1992 e 1994, cujo exame permite observar como evoluiu a proposta.

A primeira referência sobre a discussão de uma legislação específica para os jardins botânicos registrada, na folha 2 do Processo, é uma carta da Presidenta da Rede Brasileira de Jardins Botânicos- RBJB, datada de 25 de setembro de 1992, na qual convida os participantes do III Congresso Internacional de Conservação em Jardins Botânicos para uma palestra, “... finda a qual pretende-se extrair uma conclusão que permita definir diretrizes para a atuação dos jardins botânicos brasileiros e instituições afins", fazendo parte da programação a discussão da legislação para jardins botânicos.

$\mathrm{Na}$ folha 3 daquele processo, há a informação de que já havia sido discutido um documento preliminar a respeito, em janeiro de 1992, durante o Congresso Nacional de Botânica, demonstrando que a preocupação em "normatizar as ações" dos jardins botânicos, no Brasil, é anterior à CDB.

A idéia inicial era elaborar um Projeto de Lei, a ser encaminhado para aprovação pelo Congresso Nacional, com o objetivo de: 
“... normatizar as ações destas instituições, propondo condições mínimas de atividades a serem implantadas, coordenadas e fiscalizadas pelos órgãos nacionais de apoio à pesquisa $\mathrm{e}$ conservação ambiental." (Fl.03)

A proposta de regulamentação dos jardins botânicos, embora tenha partido da iniciativa dessas próprias instituições, encontrou ressonância nos órgãos federais responsáveis pela elaboração e aplicação da política ambiental no País. O Ministério do Meio Ambiente e o IBAMA colaboraram ativamente na formulação da Resolução 266. Dessa forma, e visto que incorpora diretrizes de conservação ratificadas pelo País, pode ser então caracterizada, antes de um mero instrumento normativo, como um instrumento de aplicação de uma política pública para jardins botânicos.

Concebida inicialmente como um Projeto de Lei, a opção pela substituição do instrumento jurídico deveu-se à constatação de que o tempo decorrido para a sua edição seria significativamente menor do que para a edição da Lei, e ao entendimento de que tal solução atenderia da mesma forma aos objetivos propostos pelos jardins botânicos brasileiros, naquele momento.

A substituição de instrumentos não encontrou resistências, e coube ao Ministério do Meio Ambiente sua edição, por tratar-se a matéria de normas disciplinares para os jardins botânicos em geral, já que é deste (Ministério) a atribuição de formular a política nacional de meio ambiente.

Anteriormente a proposta de Projeto de Lei já havia sido encaminhada ao CONAMA, para análise da Câmara Técnica de Ecossistemas e inclusão na pauta daquele Conselho, pois, em razão da abrangência e pertinência da matéria, fazia-se necessário ampliar a discussão entre os diversos setores envolvidos no assunto a fim de assegurar a eficiência e legitimidade da proposta.

Em 29/07/99, foi encaminhada ao MMA a proposta de Resolução CONAMA elaborada durante a Assembléia Geral Ordinária da Rede Brasileira de Jardins Botânicos, de 21/07/99, no $50^{\circ}$ Congresso Nacional de Botânica, em Blumenau, tendo sido aprovada, por consenso, pelos os jardins botânicos participantes. Cada item foi exaustivamente debatido, objetivando incluir na minuta de Resolução o que de mais atual se praticava na regulamentação de jardins botânicos, a nível internacional

Finalmente, a Resolução/CONAMA 266 foi aprovada em 03/08/2000 pelo CONAMA e publicada no Diário Oficial da União em 27/09/00.

Merece destaque uma questão que deixou de ser incorporada na versão da 266, encaminhada para ser aprovada pelo CONAMA: a capacidade de ingerência, reservada aos jardins, nas áreas de entorno, prevendo, inclusive, o poder de exigir Avaliação de Impacto Ambiental - AIA e Relatório de Impacto Ambiental RIMA, para os projetos a serem nela desenvolvidos.

Tal ingerência foi prerrogativa dos jardins botânicos, considerados legal e explicitamente como Unidades de Conservação, até a publicação do Sistema Nacional de Unidades de Conservação, SNUC: ao não estarem incluídos neste Sistema, e por não estar este aspecto contemplado na Resolução 266, os jardins botânicos perderam esta prerrogativa, importante para protegerem-se das perturbações antrópicas que os acometem, especialmente aqueles incrustados na malha urbana das grandes cidades.

Merecem destaque,ainda, por sua relevância, dois pareceres a respeito da proposta de Resolução: o parecer da Câmara Técnica Permanente de Ecossistemas/ CONAMA, de 05/03/98 (F1.96), e o da Secretaria de Desenvolvimento Científico do MCT, 24/09/98 (Fl. 124).

O primeiro, em seu último parágrafo registra que o instrumento julgado mais adequado para regular os jardins botânicos seria uma lei:

“Tendo em vista, porém, a provável demora na promulgação da lei..., uma resolução do CONAMA poderá ser solução temporária adequada, com maior peso do que uma Portaria 
A regulamentação dos jardins botânicos brasileiros: ampliando as perspectivas de conservação da

do IBAMA, enquanto transitar o projeto de lei referente ao tema".

O segundo parecer sugere:

“... caso haja aprovação da presente proposta de Resolução pelo CONAMA, seu posterior encaminhamento à Casa Civil da Presidência da República para avaliação da oportunidade de a matéria vir a ser objeto de Lei”.

\section{A Resolução 266 - um instrumento para o desenvolvimento dos jardins botânicos}

A elaboração de um instrumento específico de regulamentação dos jardins botânicos brasileiros, materializado na Resolução CONAMA 266, foi um processo com duração registrada de 8 anos, de 1992 a 2001, no qual foi amadurecida uma forma que a qualifica como um instrumento para o desenvolvimento dos jardins botânicos numa perspectiva conservacionista.

A definição legal dos jardins botânicos e de seus objetivos, passa a constituir um alvo, um ponto de chegada para estas instituições, cujo trajeto é desenhado pelas categorias estabelecidas para sua classificação.

Desta forma, a Resolução 266 passa a ser instrumento de uma estratégia de apoio e alavancagem dos jardins, na medida que os define legalmente numa perspectiva de conservação dos recursos florísticos do país, e estabelece seus objetivos em consonância com o que é proposto como a missão global dessas instituições pelas Normas Internacionais de Conservação para Jardins Botânicos.

A definição legal de um jardim botânico brasileiro é a seguinte: “...área protegida, constituída, no seu todo ou em parte, por coleções de plantas vivas cientificamente reconhecidas, organizadas, documentadas e identificadas, com a finalidade de estudo, pesquisa e documentação do patrimônio florístico do país, acessível ao público, no todo ou em parte, servindo à educação, à cultura, ao lazer e à conservação do meio ambiente."

Pela Resolução 266 um jardim botânico deverá ainda contar, preferencialmente, com áreas anexas preservadas, em forma de arboreto ou unidades de conservação, visando completar o alcance de seus objetivos, assim estabelecidos:

I - promover a pesquisa, a conservação, a preservação, a educação ambiental e o lazer compatível com a finalidade de difundir o valor multicultural das plantas e sua utilização sustentável;

II - proteger, inclusive por meio de tecnologia apropriada de cultivos, espécies silvestres, ou raras, ou ameaçadas de extinção, especialmente no âmbito local e regional, bem como resguardar espécies econômica e ecologicamente importantes para a restauração ou reabilitação de ecossistemas;

III - manter bancos de germoplasma ex situ e reservas genéticas in situ;

IV - realizar, de forma sistemática e organizada, registros e documentação de plantas, referentes ao acervo vegetal, visando plena utilização para conservação e preservação da natureza, para pesquisa científica e educação;

$\mathrm{V}$ - promover intercâmbio científico, técnico e cultural com entidades e órgãos nacionais e estrangeiros;

VI - estimular e promover a capacitação de recursos humanos.

Foi também criada pela Resolução 266, e posteriormente instituída pela Portaria Ministerial 287, a Comissão Nacional de Jardins Botânicos, CNJB, com a seguinte composição:

I - dois representantes do Ministério do Meio Ambiente;

II - dois representantes da Rede Brasileira de Jardins Botânicos;

III - dois representantes do Ministério da Ciência e Tecnologia;

IV - um representante da Sociedade Botânica do Brasil.

Constando como atribuições dessa Comissão, além de deliberar sobre os pedidos de criação e enquadramento de jardins 
botânicos, monitorar e avaliar a atuação dessas instituições.

Para classificar os jardins botânicos nas categorias "A", "B" e "C", estabelecidas pela Resolução 266, a CNJB deverá observar critérios técnicos, por ela mesma definidos, que levem em conta a infra-estrutura, a qualificação do corpo técnico e de pesquisadores, os objetivos, localização e especialização operacional de cada instituição.

Dentre outras questões importantes registramos, ainda, das deliberações dessa Resolução que: a importação, a exportação, o intercâmbio, bem como qualquer outra forma de acesso a vegetais ou a partes deles, oriundos da flora nativa ou exótica, pelos jardins botânicos, obedecerá à legislação específica, bem como a comercialização de plantas ou de partes delas . Estas questões estão sendo hoje reguladas pela MP 2186 de 23/08/2001.

A proposta de regulamentação dos jardins botânicos, embora tenha partido da iniciativa dessas próprias instituições, encontrou ressonância nos órgãos federais responsáveis pela elaboração e aplicação da política ambiental no País. O Ministério do Meio Ambiente e o IBAMA colaboraram ativamente na formulação da Resolução 266. Dessa forma, e visto que incorpora diretrizes de conservação ratificadas pelo País, pode ser caracterizada, antes de mero instrumento normativo, como um instrumento de aplicação de uma política pública para jardins botânicos.

\section{A implementação da Resolução 266}

A medida inicial para a implementar a Resolução 266 foi a edição da Portaria/ MMA/ 267, de 2000, que nomeou a CNJB. Essa Comissão é composta majoritariamente por entidades integrantes da estrutura do Poder Público, a quem compete regular a questão dos Jardins Botânicos, e sua estrutura e atribuições já foram anteriormente apresentadas.

Em março de 2001, na sua reunião de instalação, visando agilizar o processo, a CNJB decidiu solicitar ao MMA a delegação, para o JBRJ, das atribuições referentes aos procedimentos iniciais para o registro e enquadramento dos jardins botânicos. Essa delegação foi concedida pela Resolução/ CONAMA 287/2001.

Nessa primeira reunião foi, ainda, aprovado o conteúdo do que viria a ser a Moção CONAMA n ${ }^{\circ} 13$, de 07/2001, já vista na parte sobre legislação, e criada uma secretaria técnica da CNJB, com a atribuição de apoiar e assessorar as atividades da Comissão.

\section{A busca de um método para enquadramento dos jardins botânicos}

A secretaria técnica da CNJB elaborou o estudo: "Subsídios para a Discussão de um Método de Enquadramento dos Jardins Botânicos, Segundo a Resolução 266/ CONAMA" (vide anexo2), com dupla finalidade: subsidiar a discussão da CNJB a respeito de um método e dos critérios para o enquadramento dos jardins botânicos e apresentar uma proposta para a comprovação documental dos processos, requerida por seu caráter cartorial.

Tais subsídios foram elaborados a partir de um exercício feito, para o enquadramento do JBRJ na categoria "A", cuja metodologia constituiu na análise das possíveis interpretações de cada item da Resolução 266, obtidas em entrevistas realizadas junto a pessoas qualificadas para avaliar as condições do JBRJ em cada quesito, (Parreiras, 2001).

Daquela análise foram geradas as observações e recomendações que subsidiaram a discussão da CNJB sobre como proceder ao enquadramento e definir a proposta de comprovação documental adotada para cada item de exigência.

Os critérios para enquadramento são norteados pelo princípio de que cada jardim botânico tem uma missão própria, e esta determina sua estrutura, funcionamento e perfil. Dessa forma, é o caráter particular de cada instituição o balizador dos critérios para avaliar se ela atende, ou não, as exigências para enquadramento definidas na Resolução 266.

Os esforços em desenvolver um caminho 
A regulamentação dos jardins botânicos brasileiros: ampliando as perspectivas de conservação da

possível para enquadrar os jardins botânicos, de acordo com a Resolução 266, permitiram concluir que:

I - A missão institucional e o tipo de jardim devem ser considerados na definição dos critérios para enquadrar os jardins botânicos.

II - A avaliação da maioria dos itens de exigências da Resolução 266, para cada uma das três categorias: A, B e C, deve ser fundamentada em critérios flexíveis, de forma a viabilizar o enquadramento de instituições com especificidades que guardam grandes diferenças.

III - Deve ser evitado o risco de estreitar conceitos que aparecem nas exigências, tais como o de "quadro técnico", entre outros, em definições que dificultariam ou inviabilizariam identificá-los em uma gama de instituições tão diversas.

\section{A estruturação de um sistema de registro para os jardins botânicos}

A Lei n 10.316, de 06/12/01, que transforma o JBRJ em autarquia federal, estabelece como sua atribuição "...controle e operacionalização do Sistema Nacional de Registro dos Jardins Botânicos”, o que vem consolidar o papel que lhe é atribuído pela Resolução 266.

Assim, o registro e o enquadramento dos jardins botânicos, embora atrelados, pertencem a instâncias distintas de decisão: o enquadramento é atribuição da CNJB, mas o registro deverá ser emitido pelo Ministério do Meio Ambiente, através do JBRJ .

O Sistema de Registro para Jardins Botânicos, que também foi submetido à avaliação da CNJB; prevê as ações e os instrumentos necessários à sua operacionalização e seu fluxograma engloba as atividades do processo de enquadramento e registro.

O sistema está sendo implementado no JBRJ, através do Sistema Nacional de Registro dos Jardins Botânicos, criado com a finalidade de abrigar a secretaria técnica da CNJB e, principalmente, atender às novas atribuições legais, que emprestam ao Instituto um caráter especial de agência reguladora.

\section{Implementando a Resolução 266}

As medidas implementadas, comentadas acima, traduzem o esforço da CNJB e do JBRJ para o cumprimento da Resolução 266. O prazo legal para os jardins botânicos, já existentes à época da edição desta Resolução, adequaremse às novas exigências expirou formalmente no dia 03/08/2002.

Para viabilizar o cumprimento desse prazo e garantir uma flexibilidade na aplicação da Resolução 266, capaz de transformá-la em um instrumento de incentivo ao desenvolvimento dos jardins botânicos, a CNJB adotou as seguintes medidas:

- Decidiu que receberão registro provisório com enquadramento inicial na categoria $\mathrm{C}$, todos os jardins botânicos que comprovarem atender a pelo menos seis dos itens de exigência para a categoria requerida.

- Disponibilizou um produto, elaborado pela secretaria técnica, para orientar os jardins botânicos quanto aos procedimentos necessários à sua adequação legal. (anexo 4) - Definiu um prazo para requisição de registro e enquadramento: de 20/10/2001 à 04/03/2002. - O início da avaliação dos jardins botânicos, a partir do exame da documentação referente aos processos de registro e enquadramento, em 20/ 03/2002.

- A Comissão poderá decidir pelo exame in loco das condições dos jardins botânicos, sempre que achar conveniente para a maior clareza e objetividade do enquadramento.

Por serem novos, tanto a Resolução 266, quanto o método para enquadramento e o próprio sistema de registro, ainda carecem de validação e do crivo da eficácia.

A validade e eficácia destes instrumentos, inclusive da própria Resolução 266, puderam ser testadas, pela CNJB, na rodada de avaliação e enquadramento dos jardins botânicos, realizadas em março de 2002, quando foram examinados os processos dos jardins que 
solicitaram o registro e enquadramento, para sua adequação legal .

Das 31 instituições existentes no País que poderiam, a princípio, solicitar registro e serem classificadas enquanto jardins botânicos, 18 o fizeram. Este número foi avaliado, pela CNJB como bastante satisfatório.

Para realizar o trabalho de avaliação a Comissão foi dividida em quatro equipes de dois conselheiros, sendo um deles o relator, e a cada uma coube o exame de um determinado número de processos. Aos relatores coube elaborar o parecer sobre o enquadramento, ou não, de cada instituição avaliada pela equipe. Finalmente a Comissão, reunida, discutiu cada um desses pareceres e emitiu um parecer oficial.

Receberam o registro e enquadramento definitivo, na categoria $B$, quatro instituições e na categoria $C$ uma. Foram enquadrados na categoria B: Jardim Botânico de Brasília, Jardim Botânico de Porto Alegre, Jardim Botânico da FZB de Belo Horizonte e o Instituto de Pesquisas Jardim Botânico do Rio de Janeiro e na categoria C: o Jardim Botânico Museu de Biologia Melo Leitão, Santa Teresa, ES.

Têm já garantido o registro $\mathrm{e}$ enquadramento provisório na categoria $\mathrm{C}$ conferido pelo prazo de um ano àqueles Jardins Botânicos que alcançaram, na categoria requerida, pontuação igual ou maior do que seis; as seguintes instituições: Jardim Botânico de Lajeado, RS; Jardim Botânico Adelmo Piva Júnior, Paulínia, SP; Jardim Botânico Municipal Francisca M G Rischbieter, Curitiba, PR; o Jardim Botânico de São Paulo, SP; o Bosque Rodrigues Alves e o Museu Paraense Emílio Goeldi, Belém, PA.

Essas instituições poderão, até 30 de junho de 2002, solicitar novamente o enquadramento definitivo nas categorias antes requeridas, se assim desejarem. Neste caso, seus processos deverão ser complementados com informações que comprovem as necessidades de adequação recomendadas pela CNJB nessa primeira avaliação. Do contrário, daqui a um ano passarão por nova avaliação, para receberem, então, enquadramento definitivo.
Outros sete jardins botânicos não puderam ser registrados, por não atenderem as exigências mínimas para registro e enquadramento provisório, ou por terem apresentado relatórios mal estruturados. Foi, ainda, recomendado o fechamento temporário de um deles, para reestruturação, e outro foi considerado em fase de implantação, podendo requerer novamente o registro no prazo de um ano. Os demais, no entanto, terão o tempo até 30/06/02, para adequar seus relatórios e atender às exigências de registro e enquadramento.

Aquelas instituições que não solicitaram o registro e enquadramento, no prazo estabelecido para esta primeira avaliação, poderão fazê-lo somente até $30 / 06 / 02$, pois a CNJB necessita de tempo suficiente para fazer as novas avaliações, já que o prazo final, para adequação dos jardins botânicos já existentes, foi estabelecido para 03/08/2002, pela Resolução 266.

Findo estes prazos, a Comissão informará, ao MMA e a todas as instituições que apoiam os jardins botânicos, a lista daqueles que deixaram de solicitar o registro, recomendando que não sejam acolhidas suas demandas. Informará, também, os que foram registrados e aqueles que não reuniram condições, ainda, para obter o registro neste processo de avaliação, mas que estarão buscando atender, para futuro registro e enquadramento, as recomendações da CNJB.

Era provável, e desejável, que o processo evidenciasse, no momento de validação dos seus instrumentos, as fragilidades destes, bem como os caminhos para o seu aperfeiçoamento. As orientações para avaliar e elaborar os processos foram validadas, pela própria avaliação feita pela Comissão, e por inúmeros relatórios perfeitamente estruturados de acordo com elas. Quanto aos relatórios que caíram em exigências, era nítido que sua elaboração não seguiu aquelas instruções.

A experiência evidenciou também a importância de aperfeiçoar a Resolução 266, na perspectiva de elaboração de um projeto de Lei para regulamentar os jardins botânicos. 
A regulamentação dos jardins botânicos brasileiros: ampliando as perspectivas de conservação da biodiversidade

De plano, fez-se sentir a necessidade de estabelecer diferentes níveis de classificação em cada uma das categorias de enquadramento, pois da maneira como estão apresentadas provocam distorções importantes: acabaram tendo que ser enquadrados, na mesma categoria, jardins que, embora atendam formalmente os requisitos, apresentam condições e qualidades muito diferenciadas. O JBRJ, por exemplo, ficou no mesmo nível de jardins cuja estrutura é evidentemente muito inferior à sua.

\section{Desafios e propostas}

Como pretendemos ter demonstrado neste trabalho, a legislação ambiental brasileira está em construção - ora consolidando, ora apontando elementos para uma política nacional de meio ambiente, na mais ampla das perspectivas: de conservação da diversidade biológica e sustentabilidade do uso dos recursos naturais e do desenvolvimento.

Desta forma, é possível ver a Resolução 266 como um ponto de partida, Isto traz o desafio de encontrar resposta para questões como:

- Qual a conseqüência para as instituições que não se registrarem, ou não alcançarem as condições para enquadramento, além do risco das sanções legais previstas para o não cumprimento de norma federal?

- Qual a importância da normatização das atividades dos jardins botânicos, frente aos problemas que o país enfrenta em relação à biopirataria, ao acesso aos recurso $\mathrm{s}$ florísticos e à justa repartição dos benefícios deles advindos, por exemplo?

- Como estender aos jardins botânicos as prerrogativas das Unidades de Conservação relativas à capacidade de ingerência no seu entorno e ao acesso aos recursos oriundos das multas por crimes ambientais?

- Como promover os meios para o fomento do seu desenvolvimento institucional e científico?

As respostas para essas questões, suscitadas pela análise do processo de regulamentação dos jardins botânicos, virão deste próprio processo. No entanto, alguns caminhos já podem ser apontados:
- Resgatar as propostas de transformar em Lei a regulamentação dos jardins botânicos, fazendo os ajustes necessários, que a experiência da aplicação da 266 vier a apontar.

- Incorporar nessa lei as prerrogativas das Unidades de Conservação: de ingerência na área de entorno e acesso aos recursos advindos da multas por crimes ambientais, além de outras que sejam convenientes para os propósitos de seu desenvolvimento institucional.

- Estimular a realização de estudos sobre os diversos aspectos implicados no desenvolvimento dos jardins botânicos: institucionais, administrativos, recursos necessários (financeiros, tecnológicos e científicos).

- Dar conseqüência prática à atribuição legal do JBRJ, Lei 10.316, de 06/12/2001, efetivando o Programa de Apoio à Criação, Implantação e Desenvolvimento para os Jardins Botânicos, a partir das soluções que o próprio processo de avaliação aponta.

\section{Considerações finais}

A Resolução CONAMA 266 deve ser vista e entendida à luz das principais questões ambientais que compõem o momento histórico no qual vivemos. Muito além de um mero instrumento normativo, ela deve ser entendida como um elemento importante para o desenvolvimento dos jardins botânicos, na perspectiva colocada pela necessidade da conservação da diversidade biológica e da promoção do uso sustentável dos recursos naturais.

Vista assim, pode ser considerada como indicativa de um ponto de chegada para o desenvolvimento dos jardins botânicos: na medida em que estabelece parâmetros para a sua classificação, aponta, indiretamente, os meios para alcançá-los, permitindo visualizar essa chegada em horizontes de tempo diferenciados, de acordo com as possibilidades de cada instituição.

Por outro lado, pode ser vista como um ponto de partida, na medida em que é importante trabalhar pelo aperfeiçoamento da 
legislação ambiental brasileira e, nesta, a legislação específica dos jardins botânicos.

É importante salientar que o processo de enquadramento colabora efetivamente para o desenvolvimento dos jardins botânicos brasileiros, na medida em que o caminho escolhido pela CNJB, para analisar essas instituições, permite apontar soluções para grande parte dos problemas por elas enfrentados.

Finalmente, cabe reafirmar que implementar estratégias de conservação implica na combinação de políticas, ações e saberes diversos, bem como numa estruturação institucional capaz de sustentar essa implementação; e que somente a vontade política e o compromisso com a conservação e a sustentabilidade poderão garantir a formulação e o uso de uma legislação regulatória como instrumento impulsionador de políticas públicas para o desenvolvimento institucional dos jardins botânicos.

\section{REFERÊNCIAS BIBLIOGRÁFICAS}

Brasil, Decreto legislativo ${ }^{\circ} 2$, de 1994, ratifica a Convenção Sobre Diversidade Biológica$\mathrm{CDB}$

CMMAD - Comissão Mundial sobre Meio Ambiente e Desenvolvimento. 1998.

Nosso Futuro Comum, Rio de Janeiro, FGV, $1^{a}$ edição, 428 p.

Costa, F.A.P.L. 2001. Evolução interrompida. Disponível em http:/www.uol.com.br/ ambienteglobal/site/artigos/arquivo/ 1244_at.htm. Acesso em 15/01/2002.

Dean, W. 1996. A ferro e fogo: a história da devastação da Mata Atlântica brasileira. São Paulo: Companhia das Letras, $482 \mathrm{p}$.

Lagos, S.W. 1998. Biodiversidad, Globalizacion y Desarrollo del Gran Caribe. In: XI Congresso de Economistas de América Central y el Caribe, Honduras, 17 p.

Maimon, D. 1994. A economia e a problemática ambiental. In: Vieira, P.F \& Maimon, D. (org.). As ciências sociais e a questão ambiental: rumo à interdisciplinaridade. Belém, APED, Universidade Federal do Pará, p. 45-78.

BGCI et al. 2001. Normas Internacionais de Conservação para Jardins Botânicos. Rio de Janeiro, 109 p.

Glowka, L. et al. 1996. Guia del Convenio sobre la Diversidad Biológica. UICN, Unión Mundial para la Naturaleza, 169 p.

Parreiras, O.M.U.S. 2001. Subsídios para a discussão de um método de enquadramento dos jardins botânicos, segundo a Resolução 266/CONAMA. Rio de Janeiro, JBRJ, 11p.

Processo $\mathrm{n}^{\circ}$ 02001.000117/94-16 IBAMA/ MMA, iniciado em 1992.

Rauer, G. et. al. 2000. The Convention on Biodiversity and Botanic Gardens. In: Botanic Gardens and Biodiversity, Federal Agency for Nature Conservation. Bonn, $67 \mathrm{p}$.

Reigota, M. 2001. Meio ambiente e representação social. São Paulo, Cortez, $87 \mathrm{p}$.

Resolução CONAMA 266, DE 03/08/2000.

Rocha, Y.T. 1999. Dos antigos ao atual jardim botânico de São Paulo. Dissertação para obtenção do titulo de Mestre em Ciências, Universidade de São Paulo.

Tuxill, J. 1999. Reconhecendo os benefícios da Biodiversidade Vegetal. Estado do mundo. Salvador, Editora UMA, 261 p.

Unger, N.M. 2001. Da foz à nascente: o recado do Rio. São Paulo, Editora Cortez e Campinas, Editora da Unicamp, 201 p. 